\title{
Significantly higher frequencies of presence of serum autoantibodies in Chinese patients with oral lichen planus
}

\author{
Julia Yu-Fong Chang ${ }^{1,2}$, Chun-Pin Chiang ${ }^{1,2}$, Chuhsing Kate Hsiao ${ }^{3}$, Andy Sun ${ }^{1,2}$ \\ ${ }^{1}$ School of Dentistry, College of Medicine, National Taiwan University, Taipei, Taiwan; ${ }^{2}$ Department of Dentistry, National Taiwan \\ University Hospital, College of Medicine, National Taiwan University, Taipei, Taiwan; ${ }^{3}$ Department of Public Health, College of \\ Public Health, National Taiwan University, Taipei, Taiwan
}

BACKGROUND: Previous studies have shown the presence of serum anti-nuclear (ANA), anti-smooth muscle (SMA), anti-mitochondrial (AMA), anti-gastric parietal cell (GPCA), anti-thyroglobulin (TGA) and anti-thyroid microsomal autoantibodies (TMA) in small groups of patients with oral lichen planus (OLP).

METHODS: In this study, the serum levels of ANA, SMA, AMA, GPCA, TGA and TMA were measured in a group of 320 Chinese OLP patients and 53 healthy control subjects to assess whether Chinese OLP patients had significantly higher frequencies of serum autoantibodies than healthy control subjects and to assess which risk factors had a significant influence on the possession of a specific serum autoantibody in OLP patients.

RESULTS: We found that autoantibodies were present in $195(60.9 \%)$ of the 320 OLP patients. The frequencies of presence of serum ANA (28.1\%), GPCA (26.3\%), TGA (2I.3\%) and TMA (24.4\%) in OLP patients were significantly higher than those $(5.7 \%, 1.9 \%, 1.9 \%$ and $1.9 \%$, respectively) in healthy control subjects (all $\boldsymbol{P}$-values were $<0.005)$. Forty-one (I $2.8 \%)$ OLP patients also had antihepatitis C virus antibody (HCVA) in their sera. The multivariate logistic regression found that major erosive OLP $($ EOLP) [odds ratio $(O R)=1.786$ ], TGA/TMA-positivity $(O R=2.5 I 7)$, and HCVA-positivity $(O R=2.214)$ were significant risk factors to influence ANA-positivity in OLP patients. Moreover, only major EOLP $(O R=1.879)$ and ANA-positivity $(O R=2.58 \mathrm{I})$ were significant risk factors to influence TGA/TMA-positivity in OLP patients. CONCLUSIONS: There are significantly higher frequencies of presence of ANA, GPCA, TGA and TMA in Chinese OLP patients than in healthy control subjects.

J Oral Pathol Med (2009) 38: 48-54

Keywords: anti-hepatitis C virus antibody; autoantibodies; oral lichen planus

Correspondence: Dr Andy Sun, Department of Dentistry, National Taiwan University Hospital, 1 Chang-Te Street, Taipei 10048, Taiwan. Tel: +886223123456 (ext. 7702), Fax: +886 2389 3853, E-mail: andysun7702@yahoo.com.tw

Accepted for publication April 22, 2008

\section{Introduction}

Oral lichen planus (OLP) is a chronic inflammatory oral mucosal disease. Previous study showed involvement of both antigen-specific and non-specific mechanisms in OLP. Antigen-specific mechanisms include antigen presentation by basal keratinocytes and antigen-specific keratinocyte killing by $\mathrm{CD} 8^{+}$cytotoxic $\mathrm{T}$ lymphocytes. Non-specific mechanisms include mast cell degranulation and matrix metalloproteinase activation in OLP lesions (1). Through mast cell/T-cell interactions in OLP lesions, mast cell-released cytokines, chemokines and matrix metalloproteinases can promote T-cell activation, migration, proliferation and differentiation (2). OLP is histologically characterized by liquefaction degeneration of basal epithelial cells and an intraepithelial and subepithelial infiltrate of mononuclear cells which are predominantly $\mathrm{CD} 8^{+}$. $\mathrm{CD} 4^{+}$cells are observed mainly in the deep lamina propria (3). An increase in histocompatibility leukocyte antigen (HLA)-D-related (DR)-positive $\mathrm{CD}^{+}$cells in both the local lesional tissues and peripheral lymphocytes also indicates $\mathrm{T}$-cell activation in $\operatorname{OLP}(4,5)$. The above findings suggest that OLP is a T-cell-mediated inflammatory disease.

Previous studies have shown the presence of serum autoantibodies including anti-epithelial cell, anti-nuclear (ANA), anti-smooth muscle (SMA), anti-mitochondrial (AMA), anti-gastric parietal cell (GPCA), anti-thyroglobulin (TGA), anti-thyroid microsomal (TMA) and anti-desmogleins 1 and 3 antibodies in small groups of OLP patients (all studies $n<33$ except ours $n=63$ ) (6-11). In this study, we examined the frequencies of presence of serum antoantibodies including ANA, SMA, AMA, GPCA, TGA and TMA in a large group of 320 Chinese OLP patients and in 53 healthy control subjects. We tried to find whether there were significantly higher frequencies of presence of serum autoantibodies in Chinese OLP patients than in healthy control subjects. In addition, we also used univariate and multivariate analyses to assess which risk factors had a significant influence on the possession of a specific serum autoantibody in OLP patients. 


\section{Materials and methods}

\section{Subjects}

The study group consisted of 320 OLP patients (53 men and 267 women, age range 21-83 years, mean 55.3 years) without LP of other mucosal or skin surfaces. The normal control group consisted of 53 healthy subjects (eight men and 45 women, age range 21-83 years, mean 54.7 years) without any oral mucosal or systemic diseases. All the patients and control subjects were seen consecutively, diagnosed, and treated in the Department of Oral Diagnosis of National Taiwan University Hospital from July 2004 to June 2007. OLP patients with areca quid chewing habit, hypertension and autoimmune diseases such as systemic lupus erythematosus, rheumatoid arthritis, Sjogren's syndrome, pemphigus vulgaris and cicatricial pemphigoid were excluded. In addition, none of them had taken any prescription medication at least 3 months before entering the study. The 320 OLP patients included 292 (50 men and 242 women, age range $21-83$ years, mean 55.5 years) with erosive OLP (EOLP) and 28 (three men and 25 women, age range $24-83$ years, mean 52.8 years) with non-erosive OLP (NEOLP). They were selected according to the following criteria: (i) a typical clinical presentation of radiating grayish-white Wickham striae, papules and plaques, separately or in combination (NEOLP), and erosion or ulceration on the oral mucosa (EOLP) and (ii) biopsy specimens characteristic of OLP, that is, hyperkeratosis or parakeratosis, a slightly acanthotic epithelium with liquefaction degeneration of the basal epithelial cells, a pronounced band-like lymphocytic infiltrate in the lamina propria, and the absence of epithelial dysplasia. The EOLP was further divided into the major and minor types according to criteria described previously (12). The blood samples were drawn from OLP patients and healthy control subjects. The serum autoantibody, anti-hepatitis $\mathrm{C}$ virus antibody (HCVA) and blood glucose levels were determined. This study was reviewed and approved by the Human Investigation Review Committee at the National Taiwan University Hospital.

\section{Determination of serum autoantibody levels}

The circulating ANA, SMA, AMA and GPCA were detected by the indirect immunofluorescence technique with HEp-2 cells (Medical \& Biological Laboratories Co., Nagaya, Japan; for ANA), rat kidney (for SMA and AMA) and rat stomach (for GPCA) as substrates as described previously $(10,13)$. In brief, HEp-2 cells or $5 \mu \mathrm{m}$-thick cryostat sections of substrate tissues on slides were reacted with serially diluted OLP patients' and control subjects' sera in a moist chamber at room temperature for $30 \mathrm{~min}$. The initial dilution of the patients' and control subjects' sera was 1:20 with PBS. After washing, the sections were incubated with fluorescein isothiocyanate (FITC)-labeled goat anti-human IgG antiserum (Boehringer Mannheim Biochemicals, Indianapolis, IN, USA) which had been pre-diluted and kept in dropper vial by the manufacturer and was readyto-use for another $30 \mathrm{~min}$. The sections were washed again, mounted with buffered glycerine, and examined with an Olympus fluorescence microscope (Olympus, Tokyo, Japan). Sera were scored as positive when they produced fluorescence at a dilution of 160-fold or more for ANA, and of 20-fold or more for SMA, AMA and GPCA.

TGA and TMA titers were measured by a semiquantitative microtiter particle agglutination test using Serodia-AMC kits (Fujirebio Inc., Tokyo, Japan) as described previously $(10,13)$. In brief, serial 2-fold dilutions of initial 1:20 dilutions of OLP patients' and control subjects' sera in the wells of a microtitration tray were reacted with gelatin particles sensitized with thyroglobulin or thyroid microsomal antigen at room temperature for $3 \mathrm{hr}$. The results were obtained by reading the settling patterns of the colored gelatin particles using a tray viewer. Serum containing TGA or TMA reacted with the thyroglobulin or thyroid microsomal antigen-sensitized colored gelatin particles to form a smooth mat of agglutinated particles in the microtitration tray. Negative reactions were characterized by a compact button formed by the settling of the non-agglutinated particles. TGA or TMA titers equal to or greater than 1:40 were considered positive.

\section{Determination of HCVA level}

The serum HCVA was detected by an ARCHITECT anti-HCV assay as described previously (14, 15). This assay was an automated chemiluminescent microparticle immunoassay (CMIA) based on the enzyme immunoassay (EIA) principle. In contrast to the EIA, where the antigen-antibody complexes were detected by enzymelabeled conjugate, the CMIA used acridinium labeled conjugate as detection system. The resulting chemiluminescent reaction was measured as relative light units (RLUs). ARCHITECT Anti-HCV was designed to detect antibodies to structural and non-structural proteins of the HCV genome (NS3, NS4, core). The ARCHITECT Anti-HCV assay cutoff value was calculated by the following formula: calibrator 1 mean RLU value $\times 0.074=$ cutoff RLU. ARCHITECT delivered specimen results as a ratio of the specimen signal (in RLU) to the cutoff value (S/CO). S/CO ratios of $\geq 1.00$ were considered reactive for HCVA; ratios less than 1.00 were non-reactive for HCVA.

\section{Diagnosis of diabetes mellitus}

Patients with fasting plasma glucose levels more than $126 \mathrm{mg} / \mathrm{ml}$ on two or more tests on different days or a random blood glucose level of $200 \mathrm{mg} / \mathrm{ml}$ or higher were diagnosed as having diabetes mellitus (DM).

\section{Statistical analysis}

The difference in frequency of presence of each serum autoantibody was compared between any two groups by chi-square or Fisher's exact test, where appropriate. The multivariate logistic regression was used to assess which risk factors including the age, gender, OLP type (EOLP or NEOLP), EOLP type (major or minor), and the presence of other autoantibodies, HCVA or DM had a 
significant influence on the possession of a specific serum autoantibody in OLP patients. The result was considered to be significant if the $P$-value was less than 0.05 .

\section{Results}

Autoantibodies were present in $195(60.9 \%)$ of the 320 OLP patients: $104(32.5 \%)$ had only one autoantibody, $44(13.7 \%)$ two autoantibodies, $30 \quad(9.4 \%)$ three autoantibodies, $16(5.0 \%)$ four autoantibodies and $1(0.3 \%)$ five autoantibodies. The frequencies of presence of ANA, SMA, AMA, GPCA, TGA and TMA in different groups of OLP patients and 53 healthy control subjects are shown in Table 1 . We found that the frequencies of presence of serum ANA $(28.1 \%$, $P=0.000)$, GPCA $(26.3 \%, P=0.000)$, TGA $(21.3 \%$, $P=0.002)$ and TMA $(24.4 \%, P=0.000)$ in OLP patients were significantly higher than the corresponding autoantibody frequencies $(5.7 \%, 1.9 \%, 1.9 \%$ and $1.9 \%$, respectively) in healthy control subjects. If the OLP patients were further divided into two subgroups according to the age, gender, and the presence of erosive lesion (EOLP or NEOLP), HCVA or DM, all subgroups of OLP patients also had significantly higher frequencies of presence of serum ANA, GPCA, TGA and TMA than healthy control subjects except the frequency of serum ANA in OLP patients $\leq 50$ years of age $(P=0.059$, marginal significance) and the frequency of serum TGA in male OLP patients $(P=0.118$, Table 1$)$.

Of 320 OLP patients, $41(12.8 \%)$ were also HCVApositive and $47(14.7 \%)$ also had DM (Table 1). Univariate analysis by chi-squared test showed a significant correlation between ANA-positivity and OLP patients with the age $>50$ years $(P=0.008)$, major EOLP $(P=0.000)$, or the presence of GPCA $(P=0.026)$, TGA/TMA $(P=0.000)$, or $\operatorname{HCVA}(P=0.000)$ in their sera (Table 2 ). The multivariate logistic regression found that major EOLP [odds ratio $(\mathrm{OR})=1.786, P=0.033$ ], TGA/TMA-positivity $(\mathrm{OR}=2.517, P=0.001)$ and HCVA-positivity $(\mathrm{OR}=2.214, P=0.030)$ were significant risk factors to influence ANA-positivity in OLP patients.

The GPCA-positivity in OLP patients was significantly associated with the presence of serum ANA $(P=0.026)$ or TGA/TMA $(P=0.026$, Table 3$)$, whereas neither of these two risk factors reached the significant level (both $P$-values $=0.070$ ) to influence the GPCA-positivity in OLP patients by multivariate logistic regression. Furthermore, there was a significant correlation between the TGA/TMA-positivity and major $\operatorname{EOLP}(P=0.000)$ or the presence of ANA

Table 1 Frequencies of presence of serum ANA, SMA, AMA, GPCA, TGA and TMA antibodies in different groups of OLP patients and 53 healthy control subjects

\begin{tabular}{|c|c|c|c|c|c|c|}
\hline & \multicolumn{6}{|c|}{ Autoantibodies (positive patient number, \%) } \\
\hline & $A N A$ & $S M A$ & $A M A$ & $G P C A$ & $T G A$ & $T M A$ \\
\hline$\overline{\mathrm{OLP}}(n=320)$ & $90(28.1)$ & $27(8.4)$ & $5(1.6)$ & $84(26.3)$ & $68(21.3)$ & $78(24.4)$ \\
\hline$P$-value ${ }^{\mathrm{a}}$ & 0.000 & 0.056 & 0.786 & 0.000 & 0.002 & 0.000 \\
\hline$\leq 50$ years $(n=105)$ & $19(18.1)$ & $10(9.5)$ & $2(1.9)$ & $24(22.9)$ & $20(19.0)$ & $17(16.2)$ \\
\hline$P$-value ${ }^{\mathrm{a}}$ & 0.059 & 0.048 & 0.797 & 0.001 & 0.006 & 0.016 \\
\hline$>50$ years $(n=215)$ & $71(33.0)$ & $17(7.9)$ & $3(1.4)$ & $60(27.9)$ & $48(22.3)$ & $61(28.4)$ \\
\hline$P$-value ${ }^{\mathrm{a}}$ & 0.000 & 0.072 & 0.892 & 0.000 & 0.001 & 0.000 \\
\hline Male $(n=53)$ & $13(24.5)$ & $4(7.5)$ & $0(0)$ & $14(26.4)$ & $6(11.3)$ & $8(15.1)$ \\
\hline$P$-value ${ }^{\mathrm{a}}$ & 0.015 & 0.126 & - & 0.000 & 0.118 & 0.037 \\
\hline Female $(n=267)$ & $77(28.8)$ & $23(8.6)$ & $5(1.9)$ & $70(26.2)$ & $62(23.2)$ & $70(26.2)$ \\
\hline$P$-value ${ }^{\mathrm{a}}$ & 0.000 & 0.054 & 0.691 & 0.000 & 0.000 & 0.000 \\
\hline $\operatorname{EOLP}(n=292)$ & $83(28.4)$ & $24(8.2)$ & $5(1.7)$ & $78(26.7)$ & $62(21.2)$ & $72(24.7)$ \\
\hline$P$-value ${ }^{\mathrm{a}}$ & 0.009 & 0.061 & 0.738 & 0.000 & 0.002 & 0.000 \\
\hline $\operatorname{NEOLP}(n=28)$ & $7(25.0)$ & $3(10.7)$ & $0(0)$ & $6(21.4)$ & $6(21.4)$ & $6(21.4)$ \\
\hline$P$-value ${ }^{\mathrm{a}}$ & 0.031 & 0.070 & - & 0.006 & 0.006 & 0.006 \\
\hline $\operatorname{HCVA}(+)(n=41)$ & $21(51.2)$ & $7(17.1)$ & $1(2.4)$ & $14(34.1)$ & $12(29.3)$ & $16(39.0)$ \\
\hline$P$-value ${ }^{\mathrm{a}}$ & 0.000 & 0.006 & 0.897 & 0.000 & 0.000 & 0.000 \\
\hline $\operatorname{HCVA}(-)(n=279)$ & $69(24.7)$ & $20(7.2)$ & $4(1.4)$ & $70(25.1)$ & $56(20.1)$ & $62(22.2)$ \\
\hline$P$-value $\mathrm{a}^{\mathrm{a}}$ & 0.004 & 0.090 & 0.849 & 0.000 & 0.003 & 0.001 \\
\hline $\mathrm{DM}(+)(n=47)$ & $15(31.9)$ & $2(4.3)$ & $1(2.1)$ & $16(34.0)$ & 7 (14.9) & $12(25.5)$ \\
\hline$P$-value ${ }^{\mathrm{a}}$ & 0.002 & 0.423 & 0.952 & 0.000 & 0.043 & 0.001 \\
\hline $\mathrm{DM}(-)(n=273)$ & $75(27.5)$ & $25(9.2)$ & $4(1.5)$ & $68(24.9)$ & $61(22.3)$ & $66(24.2)$ \\
\hline$P$-value ${ }^{\mathrm{a}}$ & 0.001 & 0.044 & 0.838 & 0.000 & 0.001 & 0.000 \\
\hline \multicolumn{7}{|l|}{ EOLP } \\
\hline Major $(n=128)$ & $50(39.1)$ & $9(7.0)$ & $3(2.3)$ & $41(32.0)$ & $40(31.3)$ & $43(33.6)$ \\
\hline$P$-value ${ }^{\mathrm{a}}$ & 0.000 & 0.109 & 0.628 & 0.000 & 0.000 & 0.000 \\
\hline Minor $(n=164)$ & $33(20.1)$ & $15(9.1)$ & $2(1.2)$ & $37(22.6)$ & $22(13.4)$ & $29(17.7)$ \\
\hline$P$-value ${ }^{\mathrm{a}}$ & 0.025 & 0.049 & 0.985 & 0.001 & 0.035 & 0.008 \\
\hline Healthy controls $(n=53)$ & $3(5.7)$ & $0(0)$ & $0(0)$ & $1(1.9)$ & $1(1.9)$ & $1(1.9)$ \\
\hline
\end{tabular}

HCVA, anti-hepatitis C virus antibody; DM, diabetes mellitus; OLP, oral lichen planus; EOLP, erosive OLP; NEOLP, non-erosive OLP; ANA, anti-nuclear antibody; SMA, anti-smooth muscle antibody; AMA, anti-mitochondrial antibody, GPCA; anti-gastric parietal cell antibody; TMA; anti-thyroid microsomal antibodies; TGA, anti-thyroglobulin antibody.

${ }^{a}$ Comparison between healthy control and any other groups by chi-squared or Fisher's exact test, where appropriate. 
Table 2 Univariate analysis of correlation between the presence of ANA and other affecting factors in OLP patients

\begin{tabular}{|c|c|c|c|}
\hline & $\begin{array}{l}A N A(+) \\
(n=90)\end{array}$ & $\begin{array}{l}A N A(-) \\
(n=230)\end{array}$ & $\begin{array}{c}P \text {-value } \\
\text { (chi-squared test) }\end{array}$ \\
\hline Age & & & 0.008 \\
\hline$\leq 50$ & 19 & 86 & \\
\hline$>50$ & 71 & 144 & \\
\hline Gender & & & 0.638 \\
\hline Male & 13 & 40 & \\
\hline Female & 77 & 190 & \\
\hline OLP type & & & 0.869 \\
\hline EOLP & 83 & 209 & \\
\hline NEOLP & 7 & 21 & \\
\hline EOLP type & & & 0.000 \\
\hline Major & 50 & 78 & \\
\hline Minor & 33 & 131 & \\
\hline GPCA & & & 0.026 \\
\hline Positive & 32 & 52 & \\
\hline Negative & 58 & 178 & \\
\hline TGA or TMA & & & 0.000 \\
\hline Positive & 44 & 53 & \\
\hline Negative & 46 & 177 & \\
\hline SMA & & & 0.394 \\
\hline Positive & 10 & 17 & \\
\hline Negative & 80 & 213 & \\
\hline AMA & & & 0.925 \\
\hline Positive & 2 & 3 & \\
\hline Negative & 88 & 227 & \\
\hline HCVA & & & 0.000 \\
\hline Positive & 21 & 20 & \\
\hline Negative & 69 & 210 & \\
\hline DM & & & 0.653 \\
\hline Positive & 15 & 32 & \\
\hline Negative & 75 & 198 & \\
\hline
\end{tabular}

HCVA, anti-hepatitis C virus antibody; DM, diabetes mellitus; OLP, oral lichen planus; EOLP, erosive OLP; NEOLP, non-erosive OLP; ANA, anti-nuclear antibody; SMA, anti-smooth muscle antibody; AMA, anti-mitochondrial antibody, GPCA; anti-gastric parietal cell antibody; TMA; anti-thyroid microsomal antibodies; TGA, anti-thyroglobulin antibody.

$(P=0.000)$, GPCA $(P=0.026)$ or $\operatorname{HCVA}(P=$ 0.027 ) in OLP patients (Table 4). The multivariate logistic regression found that only major EOLP $(\mathrm{OR}=1.879, P=0.016)$ and ANA-positivity $(\mathrm{OR}=$ $2.581, P=0.001)$ were significant risk factors to influence TGA/TMA-positivity in OLP patients. However, the presence of SMA or AMA in OLP patients was not related to the affecting factors such as the age, gender, OLP type, EOLP type, and the presence of other autoantibodies, HCVA or DM in OLP patients (Tables 5 and 6).

We further calculated the overlap of serum autoantibodies in 320 OLP patients. If 320 OLP patients were divided into three subgroups according to the possession of organ-specific (GPCA or TGA/TMA) or non-organspecific (ANA/SMA/AMA) serum autoantibodies: 84 $(26.3 \%)$ had GPCA, $97(30.3 \%)$ had TGA/TMA and $110(34.4 \%)$ had ANA/SMA/AMA in their sera. Of 84 GPCA-positive OLP patients, $34(40.5 \%)$ were also TGA/TMA-positive and $36(42.9 \%)$ ANA/SMA/AMA-positive. Of 97 TGA/TMA-positive OLP patients, $34(35.1 \%)$ were also GPCA-positive and 49 (50.5\%) ANA/SMA/AMA-positive. Furthermore, of 110 ANA/ SMA/AMA-positive OLP patients, $36(32.7 \%)$ also had
Table 3 Univariate analysis of correlation between the presence of GPCA and other affecting factors in OLP patients

\begin{tabular}{|c|c|c|c|}
\hline & $\begin{array}{c}G P C A(+) \\
\quad(n=84)\end{array}$ & $\begin{array}{l}G P C A(-) \\
(n=236)\end{array}$ & $\begin{array}{c}P \text {-value } \\
\text { (chi-squared test) }\end{array}$ \\
\hline Age & & & 0.407 \\
\hline$\leq 50$ & 24 & 81 & \\
\hline$>50$ & 60 & 155 & \\
\hline Gender & & & 0.888 \\
\hline Male & 14 & 39 & \\
\hline Female & 70 & 197 & \\
\hline OLP type & & & 0.702 \\
\hline EOLP & 78 & 214 & \\
\hline NEOLP & 6 & 22 & \\
\hline EOLP type & & & 0.093 \\
\hline Major & 41 & 87 & \\
\hline Minor & 37 & 127 & \\
\hline ANA & & & 0.026 \\
\hline Positive & 32 & 58 & \\
\hline Negative & 52 & 178 & \\
\hline TGA or TMA & & & 0.026 \\
\hline Positive & 34 & 63 & \\
\hline Negative & 50 & 173 & \\
\hline SMA & & & 0.788 \\
\hline Positive & 6 & 21 & \\
\hline Negative & 78 & 215 & \\
\hline AMA & & & 0.848 \\
\hline Positive & 1 & 4 & \\
\hline Negative & 83 & 232 & \\
\hline HCVA & & & 0.298 \\
\hline Positive & 14 & 27 & \\
\hline Negative & 70 & 209 & \\
\hline DM & & & 0.256 \\
\hline Positive & 16 & 31 & \\
\hline Negative & 68 & 205 & \\
\hline
\end{tabular}

HCVA, anti-hepatitis $\mathrm{C}$ virus antibody; DM, diabetes mellitus; OLP, oral lichen planus; EOLP, erosive OLP; NEOLP, non-erosive OLP; ANA, anti-nuclear antibody; SMA, anti-smooth muscle antibody; AMA, anti-mitochondrial antibody, GPCA; anti-gastric parietal cell antibody; TMA; anti-thyroid microsomal antibodies; TGA, anti-thyroglobulin antibody.

GPCA and $49(44.5 \%)$ also had TGA/TMA in their sera.

\section{Discussion}

Previous studies demonstrated an overall incidence of $27-82 \%$ for the presence of serum autoantibodies in small groups of OLP or EOLP patients (6-11). Lin et al. (6) showed the presence of serum anti-basal cell antibodies (anti-BCA) in 54\% (34/63) OLP patients. There is a decrease in the serum anti-BCA titers in six of eight anti-BCA-positive OLP patients after topical application of triamcinolone. Sun et al. (7) observed the disappearance of serum anti-BCA in three of six anti-BCA-positive EOLP patients and the disappearance of serum ANA in three EOLP patients after levamisole treatment. Lundstrom (8) demonstrated the presence of serum autoantibodies (rheumatoid factor, ANA and SMA) in $27 \%$ of the 30 OLP patients and in $9 \%$ of the 23 control subjects. Lodi et al. (9) observed the presence of circulating antibodies to epithelial antigen in $57 \%$ of 14 HCVA-positive OLP patients but in none of 14 HCVA-negative OLP patients. Carrozzo et al. (10) discovered the presence of serum 
Table 4 Univariate analysis of correlation between the presence of TGA or TMA and other affecting factors in OLP patients

\begin{tabular}{|c|c|c|c|}
\hline & $\begin{array}{c}T G A \text { or } \\
T M A(+) \\
(n=97)\end{array}$ & $\begin{array}{c}T G A \text { or } \\
T M A(-) \\
(n=223)\end{array}$ & $\begin{array}{c}P \text {-value } \\
\text { (chi-squared test) }\end{array}$ \\
\hline Age & & & 0.168 \\
\hline$\leq 50$ & 26 & 79 & \\
\hline$>50$ & 71 & 144 & \\
\hline Gender & & & 0.069 \\
\hline Male & 10 & 43 & \\
\hline Female & 87 & 180 & \\
\hline OLP type & & & 0.671 \\
\hline EOLP & 90 & 202 & \\
\hline NEOLP & 7 & 21 & \\
\hline EOLP type & & & 0.000 \\
\hline Major & 53 & 75 & \\
\hline Minor & 37 & 127 & \\
\hline ANA & & & 0.000 \\
\hline Positive & 44 & 46 & \\
\hline Negative & 53 & 177 & \\
\hline GPCA & & & 0.026 \\
\hline Positive & 34 & 50 & \\
\hline Negative & 63 & 173 & \\
\hline SMA & & & 0.565 \\
\hline Positive & 10 & 17 & \\
\hline Negative & 87 & 206 & \\
\hline AMA & & & 0.988 \\
\hline Positive & 2 & 3 & \\
\hline Negative & 95 & 220 & \\
\hline HCVA & & & 0.027 \\
\hline Positive & 19 & 22 & \\
\hline Negative & 78 & 201 & \\
\hline DM & & & 0.797 \\
\hline Positive & 13 & 34 & \\
\hline Negative & 84 & 189 & \\
\hline
\end{tabular}

HCVA, anti-hepatitis C virus antibody; DM, diabetes mellitus; OLP, oral lichen planus; EOLP, erosive OLP; NEOLP, non-erosive OLP ANA, anti-nuclear antibody; SMA, anti-smooth muscle antibody; AMA, anti-mitochondrial antibody, GPCA; anti-gastric parietal cell antibody; TMA; anti-thyroid microsomal antibodies; TGA, anti-thyroglobulin antibody.

autoantibodies including ANA, SMA, AMA, GPCA, anti-thyroid antibody in $41 \%$ of the 27 HCVA-positive OLP patients and in $52 \%$ of 23 HCVA-negative OLP patients. Recently, Lukac et al. (11) demonstrated significantly higher concentrations of circulating autoantibodies to both desmogleins 1 and 3 in 32 EOLP patients than in 50 healthy controls or in 25 patients with reticular OLP by enzyme-linked immunosorbent assay. Indirect immunofluorescence also revealed significantly higher frequencies of presence of both desmoglein autoantibodies in EOLP patients $(82 \%, 18 / 22)$ than in healthy controls $(5 \%, 1 / 20)$ or in patients with reticular OLP $(20 \%, 3 / 15)$. This study showed an overall incidence of $60.9 \%$ for the presence of serum autoantibodies in a large group of 320 OLP patients, significantly higher frequencies of presence of serum ANA, GPCA, TGA and TMA in OLP patients than in healthy control subjects, and incidences of approximately $33-51 \%$ overlap of organ-specific and nonorgan-specific serum autoantibodies in Chinese OLP patients with one or more organ-specific or non-organspecific serum autoantibodies. The above findings suggest that there are high frequencies of presence of serum
Table 5 Univariate analysis of correlation between the presence of SMA and other affecting factors in OLP patients

\begin{tabular}{|c|c|c|c|}
\hline & $\begin{array}{l}S M A(+) \\
(n=27)\end{array}$ & $\begin{array}{l}S M A(-) \\
(n=293)\end{array}$ & $\begin{array}{c}\text { P-value } \\
\text { (chi-squared test) }\end{array}$ \\
\hline Age & & & 0.784 \\
\hline$\leq 50$ & 10 & 95 & \\
\hline$>50$ & 17 & 198 & \\
\hline Gender & & & 0.988 \\
\hline Male & 4 & 49 & \\
\hline Female & 23 & 244 & \\
\hline OLP type & & & 0.922 \\
\hline EOLP & 24 & 268 & \\
\hline NEOLP & 3 & 25 & \\
\hline EOLP type & & & 0.661 \\
\hline Major & 9 & 119 & \\
\hline Minor & 15 & 149 & \\
\hline ANA & & & 0.394 \\
\hline Positive & 10 & 80 & \\
\hline Negative & 17 & 213 & \\
\hline GPCA & & & 0.788 \\
\hline Positive & 6 & 78 & \\
\hline Negative & 21 & 215 & \\
\hline TGA or TMA & & & 0.565 \\
\hline Positive & 10 & 87 & \\
\hline Negative & 17 & 206 & \\
\hline AMA & & & 0.899 \\
\hline Positive & 0 & 5 & \\
\hline Negative & 27 & 288 & \\
\hline HCVA & & & 0.067 \\
\hline Positive & 7 & 34 & \\
\hline Negative & 20 & 259 & \\
\hline DM & & & 0.405 \\
\hline Positive & 2 & 45 & \\
\hline Negative & 25 & 248 & \\
\hline
\end{tabular}

HCVA, anti-hepatitis C virus antibody; DM, diabetes mellitus; OLP, oral lichen planus; EOLP, erosive OLP; NEOLP, non-erosive OLP; ANA, anti-nuclear antibody; SMA, anti-smooth muscle antibody; AMA, anti-mitochondrial antibody, GPCA; anti-gastric parietal cell antibody; TMA; anti-thyroid microsomal antibodies; TGA, anti-thyroglobulin antibody.

autoantibodies in OLP patients and these autoantibodies may disappear after corticosteroid or immunomodulator treatment.

The mechanisms for the induction and production of various autoantibodies in the sera of OLP patients are still not clear. The histology of OLP is characterized by liquefaction degeneration of basal epithelial cells and a subepithelial band-like infiltrate of majorly $\mathrm{T}$ lymphocytes and minorly B lymphocytes and macrophages (16). T-cell activation in OLP has been indirectly proven by the increase in HLA-DR-positive $\mathrm{CD}^{+}$cells in both the local lesional tissues (4) and peripheral lymphocytes (5). Moreover, a significant increase of Langerhans cells is found in the epithelium and in the lamina propria of OLP lesion compared with normal oral mucosa (17). The nuclear antigens released from the damaged basal epithelial cells might be modified by some unknown agents from the environment and phagocytosed by the Langerhans cells, macrophages and B cells. The altered autoantigens were further processed by the antigenpresenting cells and presented to the helper/inducer $\mathrm{T}$ cells in OLP patients' oral mucosa, regional lymph nodes and blood circulation. By the help of $T$ cells, the antigen-specific activated $\mathrm{B}$ cells thus produced high 
Table 6 Univariate analysis of correlation between the presence of AMA and other affecting factors in OLP patients

\begin{tabular}{|c|c|c|c|}
\hline & $\begin{array}{l}A M A(+) \\
(n=5)\end{array}$ & $\begin{array}{l}A M A(-) \\
(n=315)\end{array}$ & $\begin{array}{c}P \text {-value } \\
\text { (chi-squared test) }\end{array}$ \\
\hline Age & & & 0.893 \\
\hline$\leq 50$ & 2 & 103 & \\
\hline$>50$ & 3 & 212 & \\
\hline Gender & & & 0.691 \\
\hline Male & 0 & 53 & \\
\hline Female & 5 & 262 & \\
\hline OLP type & & & 0.621 \\
\hline EOLP & 5 & 287 & \\
\hline NEOLP & 0 & 28 & \\
\hline EOLP type & & & 0.779 \\
\hline Major & 3 & 125 & \\
\hline Minor & 2 & 162 & \\
\hline ANA & & & 0.925 \\
\hline Positive & 2 & 88 & \\
\hline Negative & 3 & 227 & \\
\hline GPCA & & & 0.848 \\
\hline Positive & 1 & 83 & \\
\hline Negative & 4 & 232 & \\
\hline TGA or TMA & & & 0.988 \\
\hline Positive & 2 & 95 & \\
\hline Negative & 3 & 220 & \\
\hline SMA & & & 0.899 \\
\hline Positive & 0 & 27 & \\
\hline Negative & 5 & 288 & \\
\hline HCVA & & & 0.850 \\
\hline Positive & 1 & 40 & \\
\hline Negative & 4 & 275 & \\
\hline DM & & & 0.765 \\
\hline Positive & 1 & 46 & \\
\hline Negative & 4 & 269 & \\
\hline
\end{tabular}

HCVA, anti-hepatitis C virus antibody; DM, diabetes mellitus; OLP, oral lichen planus; EOLP, erosive OLP; NEOLP, non-erosive OLP; ANA, anti-nuclear antibody; SMA, anti-smooth muscle antibody; AMA, anti-mitochondrial antibody, GPCA; anti-gastric parietal cell antibody; TMA; anti-thyroid microsomal antibodies; TGA, anti-thyroglobulin antibody.

levels of ANA in the local tissues and blood circulation of OLP patients. The locally produced autoantibodies in the interstitial fluid might diffuse into blood capillaries or be drained into the lymphatic vessels, which finally reached the blood circulation.

This study showed that major EOLP, HCVA-positivity and TGA/TMA-positivity were the three major risk factors contributing to the possession of serum ANA in OLP patients. Major EOLP lesions have greater destruction of lesional oral mucosa and thus may release more nuclear antigens into the local tissues and blood circulation than minor EOLP or NEOLP lesions. In addition, HCVA-positive and TGA/TMA-positive OLP patients may have underlying chronic liver and autoimmune thyroid diseases, respectively. Therefore, they may have more nuclear antigens released in the local liver and thyroid tissues and blood circulation. By the similar mechanisms, these nuclear antigens may stimulate the antigen-specific activated $\mathrm{B}$ cells to produce more ANA. The locally secreted ANA together with the ANA produced in the blood circulation finally gave rise to significantly higher levels of serum ANA in OLP patients than in healthy control subjects. The disappearance of the anti-BCA antibodies and ANA after treatment-induced healing of the OLP lesions $(6,7)$ also suggests that the principal autoantigens come from the local OLP lesions.

Our previous study showed significantly higher frequencies of presence of HLA-DRw9 and HLATe22 antigens in Chinese OLP patients (18) and a significant association of HLA-Te22 with ANA in Chinese EOLP patients (19). HLA-DRw9 has been found to have intimate relationship with autoimmune diseases such as Graves' disease, Hashimoto's thyroiditis, myasthenia gravis and insulin-dependent DM in Chinese (20-23). HLA-DRw9 in Chinese is even considered to take the place of HLA-DR3 in Caucasians in carrying the gene which predispose to the development of autoimmune diseases $(18,21)$. Concomitant presence of OLP and underlying autoimmune thyroid disease trait in HLA-DRw9-positive Chinese patients may contribute to the possession of serum TGA or TMA in some of our OLP patients. In addition, an overlap of serum autoantibodies in the same individual is a common feature in patients with autoimmune disease. This study also showed an overlap of organ-specific and non-organ-specific serum autoantibodies in approximately $33-51 \%$ of OLP patients. These may partially explain why our OLP patients also had serum GPCA and why approximately $28 \%$ of our OLP patients have two or more kinds of autoantibody in their sera.

In conclusion, there are significantly higher frequencies of presence of ANA, GPCA, TGA and TMA in Chinese OLP patients. Major EOLP, TGA/TMA-positivity, and HCVA-positivity are significant risk factors to influence ANA-positivity in OLP patients. In addition, major EOLP and ANA-positivity had a significant influence on the possession of serum TGA/TMA in OLP patients.

\section{References}

1. Sugerman PB, Savage NW, Walsh LJ, et al. The pathogenesis of oral lichen planus. Crit Rew Oral Biol Med 2002; 13: $350-65$.

2. Zhao ZZ, Savage NW, Sugerman PB, Walsh LJ. Mast cell/T cell interactions in oral lichen planus. J Oral Pathol Med 2002; 31: 189-95.

3. Khan A, Farah CS, Savage NM, Walsh LJ, Harbrow DJ, Sugerman PB. Th1 cytokines in oral lichen planus. J Oral Pathol Med 2003; 32: 77-83.

4. Hirota J, Osaki T, Tatemoto Y. Immunohistochemical staining of infiltrates in oral lichen planus. Path Res Pract 1990; 186: 625-32.

5. Yamamoto T, Yoneda K, Ueta E, Osaki T. Cellular immunosuppression in oral lichen planus. J Oral Pathol Med 1990; 19: 464-70.

6. Lin SC, Sun A, Wu YC, Chiang CP. Presence of anti-basal cell antibodies in oral lichen planus. J Am Acad Dermatol 1992; 26: 943-7.

7. Sun A, Chiang CP, Chiou PS, Wang JT, Liu BY, Wu YC. Immunomodulation by levamisole in patients with recurrent aphthous ulcers or oral lichen planus. J Oral Pathol Med 1994; 23: 172-7. 
8. Lundstrom IM. Serum immunoglobulins and autoantibodies in patients with oral lichen planus. Int J Oral Surg 1985; 14: 259-68.

9. Lodi G, Olsen I, Piattelli A, D'Amico E, Artese L, Porter SR. Antibodies to epithelial components in oral lichen planus (OLP) associated with hepatitis $\mathrm{C}$ virus (HCV) infection. J Oral Pathol Med 1997; 26: 36-9.

10. Carrozzo M, Gandolfo S, Lodi G, et al. Oral lichen planus in patients infected or noninfected with hepatitis $\mathrm{C}$ virus: the role of autoimmunity. J Oral Pathol Med 1999; 28: 16-9.

11. Lukac J, Brozovi S, Vucicevi-Boras V, Mravak-Stipeti M, Malenica B, Kusi Z. Serum autoantibodies to desmogleins 1 and 3 in patients with oral lichen planus. Croatian Med $J$ 2006; 47: 53-8.

12. Sun A, Chia JS, Chang YF, Chiang CP. Serum interleukin-6 level is a useful marker in evaluating therapeutic effects of levamisole and Chinese medicinal herbs on patients with oral lichen planus. J Oral Pathol Med 2002; 31: 196-203.

13. Chiang CP, Hsieh RP, Chen THH, et al. High incidence of autoantibodies in Taiwanese patients with oral submucous fibrosis. J Oral Pathol Med 2002; 31: 402-9.

14. Jonas G, Pelzer C, Beckert C, Hausmann M, Kapprell HP. Performance characteristics of the ARCHITECT ${ }^{\circledR}$ AntiHCV assay. J Clin Virol 2005; 34: 97-103.

15. Echevarria JM, Avellon A, Jonas G, Hausmann M, Vockel A, Kapprell HP. Sensitivity of a modified version of the ARCHITECT ${ }^{\circledR}$ Anti-HCV test in detecting samples with immunoblot-confirmed, low-level antibody to hepatitis C virus. J Clin Virol 2006; 35: 368-72.

16. Scully C, El-Kom M. Lichen planus: review and update on pathogenesis. J Oral Pathol 1985; 14: 431-58.
17. Santoro A, Majorana A, Roversi L, et al. Recruitment of dendritic cells in oral lichen planus. J Pathol 2005; 205: 426-34.

18. Lin SC, Sun A. HLA-DR and DQ antigens in Chinese patients with oral lichen planus. J Oral Pathol 1990; 19: 298-300.

19. Sun A, Wu YC, Wang JT, Liu BY, Chiang CP. Association of HLA-Te22 antigen with anti-nuclear antibodies in Chinese patients with erosive lichen planus. Proc Natl Sci Council ROC(B) 2000; 24: 63-9.

20. Hawkins BR, Ma JT, Lam KS, Wang CC, Yeung RT. Association of HLA antigens with thyrotoxic Graves' disease and periodic paralysis in Hong Kong Chinese. Clin Endocrinol 1985; 23: 245-52.

21. Hawkins BR, Lam KS, Ma JT, Wang C, Yeung RT. Strong association between HLA DRw9 and Hashimoto's thyroiditis in Southern Chinese. Acta Endocrinol 1987; 114: $543-6$.

22. Chiu HC, Hsieh RP, Hsieh KH, Hung TP. Association of HLA-DRw9 with myasthenia gravis in Chinese. J Immunogenetics 1987; 14: 203-7.

23. Hawkins BR, Lam KS, Ma JT, et al. Strong association between HLA DR3/DRw9 heterozygosity with earlyonset insulin-dependent diabetes mellitus in Chinese. Diabetes 1987; 36: 1297-300.

\section{Acknowledgement}

This study was supported by a research grant of NSC 95-2314-B002-202 from the National Science Council, Taipei, Taiwan. 